\title{
Cartilage Oligomeric Matrix Protein Associates Differentially with Erosions and Synovitis and Has a Different Temporal Course in Cyclic Citrullinated Peptide Antibody (Anti-CCP)-positive versus Anti-CCP-negative Early Rheumatoid Arthritis
}

\author{
ANNE F. CHRISTENSEN, HANNE LINDEGAARD, KIM HØRSLEV-PETERSEN, MERETE L. HETLAND, \\ BO EJBJERG, KRISTIAN STENGAARD-PEDERSEN, SØREN JACOBSEN, TINE LOTTENBURGER, \\ TORKELL ELLINGSEN, LIS S. ANDERSEN, IB HANSEN, HENRIK SKJØDT, JENS K. PEDERSEN, \\ ULRIK B. LAURIDSEN, ANDERS SVENDSEN, ULRIK TARP, JAN PØDENPHANT, MIKKEL ØSTERGAARD, \\ and PETER JUNKER
}

ABSTRACT. Objective. Cyclic citrullinated peptide antibody (anti-CCP)-positive and anti-CCP-negative rheumatoid arthritis (RA) have been suggested as 2 distinctive disease subsets with respect to disease activity and prognosis. Previously, we proposed that anti-CCP antibodies might have a chondrocyte-suppressive effect. We aimed to compare circulating cartilage oligomeric matrix protein (COMP), a marker of cartilage turnover, in untreated anti-CCP-positive and anti-CCP-negative RA, and to study the temporal pattern of COMP through 4 years of treatment, including the relationship to imaging and clinical findings. Methods. A total of 160 patients with newly diagnosed RA who were naive to disease-modifying antirheumatic drugs were included in the CIMESTRA trial. Ninety healthy blood donors served as controls. Demographic and disease measures including Disease Activity Score in 28 joints, IgM rheumatoid factor, anti-CCP, Health Assessment Questionnaire, visual analog scale scores for pain and global and physician assessment, and magnetic resonance imaging (MRI) of the nondominant hand were recorded at baseline. COMP in serum was measured by ELISA at inclusion and serially through 4 years. Results. Median baseline COMP was higher in patients with RA [9.8 U/1 (interquartile range 8.96, 10.5)] compared with controls [8.3 U/l (IQR 7.84, 8.9); $\mathrm{p}<0.001]$ and remained elevated at 4 years [10.8 U/l (IQR 10.2, 11.7); $\mathrm{p}<0.001]$. At baseline, anti-CCP-positive patients had lower COMP than anti-CCP-negative patients $(\mathrm{p}=0.048)$. In anti-CCP-positive patients, COMP exhibited a parabolic course over 4 years, while COMP in anti-CCP-negative patients had an almost linear course. In anti-CCP-positive patients, COMP was associated with MRI edema and erosion score, while COMP was correlated with synovitis score in anti-CCP-negative individuals.

Conclusion. Our study provides additional evidence for the existence of different disease pathways in anti-CCP-positive and anti-CCP-negative subsets of RA, and evidence that anti-CCP antibodies may be implicated in the disease process by modifying cartilage metabolism. (First Release May 15 2011; J Rheumatol 2011;38:1563-8; doi:10.3899/jrheum.101241)

Key Indexing Terms:

RHEUMATOID ARTHRITIS CARTILAGE CYCLIC CITRULLINATED PEPTIDE ANTIBODY AUTOANTIBODIES SYNOVITIS CARTILAGE OLIGOMERIC MATRIX PROTEIN

From the Department of Rheumatology, Odense University Hospital, Odense; Department of Rheumatology, Copenhagen University Hospital, Herlev, Gentofte, Glostrup, Rigshospitalet; Aarhus University Hospital, Aarhus; Research Unit, King Christian X Hospital for Rheumatic Diseases, Graasten; and Institute of Clinical Research, University of Southern Denmark, Odense, Denmark.

Supported by The Danish Rheumatism Association. A.F. Christensen, PhD; P. Junker, DmSc, Professor; H.M. Lindegaard, PhD; A.J. Svendsen, PhD, Department of Rheumatology, Odense University Hospital and Institute of Clinical Research, University of Southern Denmark; T. Lottenburger, PhD; L.S. Andersen, PhD; J.K. Pedersen, PhD; K. Horslev-Petersen, DmSc, King Christian X Hospital for Rheumatic Diseases; M.L. Hetland, PhD; H. Skjødt, PhD; B.
Ejbjerg, PhD; U.B. Lauridsen, MD; M. Østergaard, PhD, DmSc, Professor, Department of Rheumatology, Copenhagen University Hospital; K. Stengaard-Pedersen, DmSc, Professor; T. Ellingsen, PhD; I. Hansen, PhD; U. Tarp, DmSc, Department of Rheumatology, Aarhus University Hospital; S. Jacobsen, DmSc, Department of Rheumatology, Copenhagen University Hospital, Rigshospitalet; J. Pødenphant, DmSc, Department of Rheumatology, Copenhagen University Hospital. Full Release Article. For details see Reprints/Permissions at jrheum.org Address correspondence to Dr. A.F. Christensen, Department of Rheumatology C, Odense University Hospital, Sdr. Boulevard 29, DK-5000 Odense C, Denmark.E-mail:a.friesgaard@gmail.com Accepted for publication March 2, 2011. 
Cartilage oligomeric matrix protein (COMP), a member of the thrombospondin glycoprotein family, is an extracellular matrix protein mainly expressed in cartilaginous tissue ${ }^{1,2,3}$. Excess release of COMP leading to elevated levels in serum has been reported in various joint diseases, osteoarthritis and rheumatoid arthritis (RA) in particular ${ }^{4}$. While some studies have suggested that increased COMP in the circulation is a predictor of joint destruction of large ${ }^{5}$ and small joints ${ }^{6,7}$ in RA, discrepant results have been reported by others $8,9,10$. These disparities may be attributable to differences in the study populations, e.g., with respect to cyclic citrullinated peptide antibody (anti-CCP) seropositivity. Thus, Turesson, et al recently reported increased COMP levels in individuals who developed RA within 1-2 years, and elevated COMP was more likely in anti-CCP-negative subjects than in anti-CCP-positive individuals ${ }^{11}$. We recently reported that the N-propeptide of collagen IIA (PIIANP), a marker of cartilage collagen anabolism, is significantly lower in anti-CCP-positive compared to anti-CCP-negative patients with $\mathrm{RA}^{12}$. As well, we found a negative correlation between PIIANP and anti-CCP titer in serum ${ }^{12}$. These observations indicate that autoimmunity reflected by anti-CCP is implicated in the pathogenesis of RA by suppressing collagen II formation. Since COMP in serum is widely considered to be a reliable molecular marker of cartilage turnover, we undertook this investigation in order to compare circulating COMP in newly diagnosed, untreated anti-CCP-positive versus anti-CCP-negative RA; to elucidate the temporal COMP pattern in these 2 subsets; and to study the relationship between COMP and baseline magnetic resonance imaging (MRI) findings and disease activity measures.

\section{MATERIALS AND METHODS}

Patients and controls. A total of 160 patients with newly diagnosed untreated RA were included in the CIMESTRA trial ${ }^{13}$. Briefly, patients fulfilled the American College of Rheumatology (ACR) 1987 revised criteria for RA ${ }^{14}$. Further inclusion criteria were disease duration $<6$ months, $\geq 2$ swollen joints at baseline, and age 18-75 years. Health Assessment Questionnaire (HAQ score, $0-3)^{15}$, visual analog scale (VAS; $1-10$ ) for pain and global and physician assessment, and Disease Activity Score in 28 joints (DAS28) ${ }^{16}$ were calculated and ACR response was recorded ${ }^{17}$. Ninety healthy blood donors (45 women, $45 \mathrm{men}$; median age $42.5 \mathrm{yrs}$, range $23-64 \mathrm{yrs}$ ) served as controls. In this healthy cohort, no other biochemical or clinical data were available and COMP was measured only once.

The RA treatment strategy aimed at achieving maximal synovitis control using methotrexate (MTX) plus cyclosporine compared to MTX and placebo $^{13}$. In addition, patients in both groups received intraarticular betamethasone injections into swollen joints $(7 \mathrm{mg} / \mathrm{l}$, maximum 4 joints or $4 \mathrm{ml}$ per visit). After one year, hydroxychloroquine was added and cyclosporine/placebo was tapered to zero, while MTX and synovitis suppression by intraarticular steroid injections into swollen joints were continued ${ }^{13}$. During an open extension through study years 3-4 the strategy of maximal synovitis suppression was pursued ${ }^{18}$. Oral glucocorticoids were allowed during the open extension study.

The trial was approved by the local ethics committee (j. no. M1959-98) and fulfilled the Declaration of Helsinki and the International Conference on Harmonisation 1996 revised guidelines for Good Clinical Practice (j. no. NCT00209859) ${ }^{13}$. Signed informed consent was obtained from all study participants.
Imaging. At baseline, 135 patients underwent contrast enhanced MRI of the nondominant wrist prior to treatment initiation. In 93 patients, 2nd-5th metacarpophalangeal (MCP) joints were imaged as well. A 0.2 Tesla dedicated extremity MRI unit (Artoscan, Esaote, Biomedica, Genova, Italy) was used in 91 patients, whereas a 1.0 Tesla and a 1.5 Tesla whole-body MRI unit (Siemens Impact and Siemens Vision, Erlangen, Germany) were used in 44 patients. MRI sequences included coronal and axial T1-weighted images (slice thickness $3 \mathrm{~mm}$; matrix $192 \times 192-384$ ) before and after intravenous gadolinium-contrast injection ( $0.1 \mathrm{mmol}$ gadolinium DTPA-BMA $/ \mathrm{kg}$ body weight; Omniscan, Amersham Health, Copenhagen, Denmark); and a coronal short-tau inversion recovery (STIR) sequence (slice thickness $3 \mathrm{~mm}$, matrix size $144-182 \times 192-256)^{19}$. MRI synovitis, edema, and erosion scores were assessed according to the OMERACT criteria ${ }^{20}$.

Laboratory measures. Serum was obtained from routine nonfasting blood samples collected between 8:00 A.M. and 2:00 P.M. Samples were allowed to clot at room temperature followed by centrifugation at $3000 \mathrm{~g}$ for $10 \mathrm{~min}$. Sera were stored at $-80^{\circ} \mathrm{C}$. COMP was measured in serum by a sandwich ELISA at baseline, after 1, 3 and 6 months, and after 1 and 4 years. The ELISA, based on 2 monoclonal antibodies directed against antigen determinants on the COMP molecule, was developed by AnaMar Medical AB, Gotenburg, Sweden ${ }^{21}$.

The reference range in our laboratory was 4.3-22.3 U/l. The interassay coefficients of variation were $11.9 \%$ and $9.8 \%$ for low (4.8-7.6 U/l) and high (9.1-14.9 U/1) concentration controls, respectively. The intraassay coefficients were $<2.5 \%$. All analyses were done in duplicate. Serial patient sera were assayed simultaneously.

C-reactive protein $(\mathrm{mg} / \mathrm{l})$ and erythrocyte sedimentation rate $(\mathrm{mm} / \mathrm{h})$ were measured using standard laboratory methods. IgM rheumatoid factor (IgM-RF; cutoff level $16 \mathrm{IU} / \mathrm{ml}$ ) and anti-CCP (cutoff level $24 \mathrm{U} / \mathrm{ml}^{22}$; EuroDiagnostica AB, Malmö, Sweden) were measured by ELISA as report$\mathrm{ed}^{22,23,24}$. Anti-CCP and RF status were not available for 1 patient.

Genomic DNA was isolated from EDTA-stabilized whole-blood samples. Human leukocyte antigen (HLA)-DRB1 genotyping for shared epitope (SE) was performed by polymerase chain reaction-based sequence-specific oligonucleotide probing, as described ${ }^{25}$. We define the SE as the presence of HLA-DRB1*04 and/or HLA-DRB1*01 and/or HLA-DRB1*10.

Statistics. All analyses were performed in Stata 9.2 (Stata Corp., College Station, TX, USA). Fisher's exact test and Mann-Whitney U test were used to compare groups for dichotomous and nondichotomous data, respectively. Linear regression modeling with adjustment for time, time-squared, sex, and age at baseline was used to analyze the course of $\operatorname{COMP}\left(y=\beta_{0}+\beta_{\text {lncomp }}+\right.$ $\left.\beta_{\text {time }}+\beta_{\text {time }}^{2}+\beta_{\text {age }}+\beta_{\text {sex }}\right)$.

Comparison between patients and controls at each timepoint was by linear regression modeling with adjustment for sex and age. Robust estimation of standard error was calculated. COMP was logarithmically transformed to approximate normal distribution. Spearman rank correlation analysis was used when appropriate. Since COMP did not differ between the 2 treatment arms, data from all the patients were pooled. Analysis was by intention-to-treat $(\mathrm{n}=$ 145). Analysis of completers was also performed and gave similar results. Missing values were assumed to be missing at random. All values are presented as median [interquartile range (IQR)] if not otherwise reported. $\mathrm{P}$ values $<0.05$ were considered statistically significant.

\section{RESULTS}

Patients and controls. Sixty-one patients (38\%) failed to complete 4 years of followup; the reasons for discontinuation were adverse events (11), lack of efficacy (10), patient's request (13), and other (27). Fifty-six (35\%) dropped out during the first 2 years. Patients who dropped out did not differ from completers with regard to demographic and clinical variables at baseline (data not shown).

Baseline characteristics in the RA population were as 
described $^{13,26}$. The 2 treatment arms did not differ in baseline characteristics except for a higher proportion of anti-CCP-positive patients in the MTX/cyclosporine versus the MTX/placebo group (57/80 vs 36/80; $\mathrm{p}<0.001)$. The need for glucocorticoids was higher during the first 2 years compared with the open extension study ${ }^{18}$. During the open extension study the cumulative dose of glucocorticoids corresponded to 0.09 (IQR 0-0.38) $\mathrm{mg}$ prednisolone per day (intraarticular and oral) compared to 0.97 (0.5-1.7) $\mathrm{mg}$ per day the first 2 years ${ }^{18}$. There was no difference in the cumulative doses of intraarticular betamethasone administered during the first 2 years between the 2 treatment arms [MTX/placebo vs MTX/cyclosporine: $14.4 \mathrm{ml}$ (7.5-19.8) vs $11 \mathrm{ml}(7-17.1) ; \mathrm{p}=0.10]$. The cumulative dose was significantly higher during the first year compared with the subsequent years ${ }^{26}$. Similarly, no difference was observed between anti-CCP-positive and anti-CCP-negative patients with respect to the total intraarticular glucocorticoid dose [12 ml (8.1-21.3) vs $12 \mathrm{ml}(7-19) ; \mathrm{p}=0.37]$. Including the cumulative dose of steroids used in the open extension study, again no difference was observed between the treatment arms or anti-CCP status (data not shown). In the RA population there was a statistically significant female preponderance $(107 / 160$ vs $45 / 90 ; p=0.01)$, and the RA patients were older than the controls [52.9 (41.8-62.5) yrs vs 42.5 (31-53) yrs; $\mathrm{p}<0.001]$.

One hundred thirty-four patients had data available for composite disease activity measures at 4-year followup, and 103/134 (77\%), 86/134 (64\%), and 89/134 (66\%) achieved ACR50, ACR70, and DAS28 <2.6, respectively.

COMP in serum. COMP exhibited an age-dependent increase in RA patients and healthy controls (rho $=0.29, \mathrm{p}=0.0002$, and rho $=0.27, \mathrm{p}=0.01$, respectively). Further, the level of COMP was significantly higher among male compared to female patients with RA [11.5 U/l (IQR 9.4-13.5) vs 8.9 U/1 (7.8-11); $\mathrm{p}<0.001]$. There was no significant difference in COMP levels between the sexes in controls $[8.5 \mathrm{U} / 1$ (7.6-10.4) vs $8.0 \mathrm{U} / 1$ (7.3-9.4); $\mathrm{p}=0.13]$.

At baseline, circulating COMP was increased in RA patients compared to controls [9.8 U/l (IQR 8.1-12.1) vs 8.3 $\mathrm{U} / 1$ (7.4-9.8); $\mathrm{p}<0.001$ ], even adjusted for age and sex $(\mathrm{p}=$ 0.001). COMP remained elevated at 4 years $[10.8(8.5-13.7)$; $\mathrm{p}<0.001]$. Stratification according to anti-CCP status showed that this increase applied to both subsets, but that COMP was significantly lower in anti-CCP-positive versus anti-CCP-negative patients [9.0 U/1 (7.8-11.8) vs $10.5 \mathrm{U} / 1$ (8.4-13.1); $\mathrm{p}=0.048$; Figure 1]. The same trend was observed after 4 years [10.2 U/1 (8.3-13.4) vs $11.7 \mathrm{U} / \mathrm{l}$ (9.6-14.3); $\mathrm{p}=0.055]$.

At baseline, COMP was also lower among IgM-RF-positive compared to IgM-RF-negative patients [9.1 U/l (IQR 7.8-11.8) vs 10.1 U/1 (8.6-13.3); $\mathrm{p}=0.047]$.

An inverse correlation was observed between COMP and anti-CCP titer at baseline (rho $=-0.17, \mathrm{p}=0.03$ ). No differ-

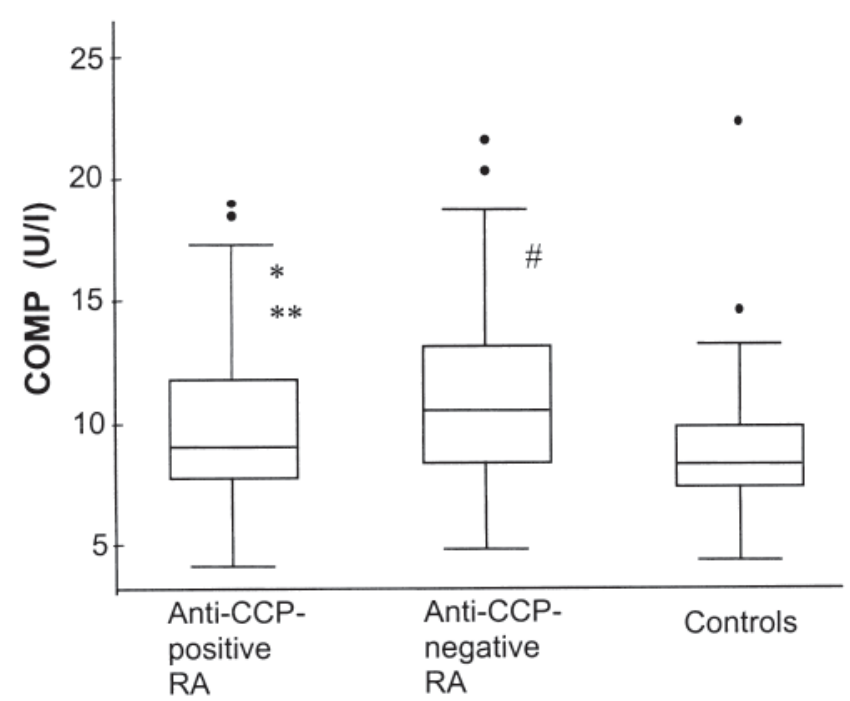

Figure 1. Circulating cartilage oligomeric matrix protein (COMP) in controls and patients with anti-CCP-positive and anti-CCP-negative newly diagnosed untreated RA. Boxes show median and interquartile range; whiskers denote 5th and 95th percentiles. Dots are outliers. *Anti-CCP-positive versus anti-CCP-negative, $\mathrm{p}=0.048$ (adjusted for sex and age, $\mathrm{p}=0.009$ ). **Anti-CCP-positive versus controls, $\mathrm{p}=0.006$ (adjusted for sex and age, $\mathrm{p}=0.04$ ). ${ }^{\# A n t i-C C P-n e g a t i v e ~ v e r s u s ~ c o n t r o l s, ~} \mathrm{p}<0.001$ (adjusted for sex and age, $\mathrm{p}<0.001)$.

ence in COMP was observed regarding shared epitope status $(\mathrm{p}=0.26)$ or smoking status $(\mathrm{p}=0.61)$.

There was no difference in baseline COMP values between patients who achieved DAS28 $<2.6$ ( $\mathrm{p}=0.48)$ or ACR70 response $(\mathrm{p}=0.21)$ compared with patients who did not achieve DAS28 $<2.6$ or ACR70 response after 4 years.

There was no difference between anti-CCP-positive and anti-CCP-negative patients with respect to demographic or clinical variables, except that anti-CCP-positive patients had fewer tender joints [8 (5-15) vs $11(7-16) ; \mathrm{p}=0.02]$ and were more frequently carriers of the SE $[82 / 93$ (88\%) vs 34/65 (52\%); p < $0.001]$ compared with anti-CCP-negative individuals.

The associations between baseline COMP and clinical variables at baseline are outlined in Table 1.

The temporal course of COMP in RA serum exhibited a parabolic configuration (Figure $2 \mathrm{~A} ; \beta_{\text {time }}{ }^{2}=-8.37 \times 10^{-6}, \mathrm{p}=$ 0.004 ) irrespective of age and sex (data not shown). This parabolic course was confined to the anti-CCP-seropositive subset $\left(\beta_{\text {time }}{ }^{2}=-1.3 \times 10^{-5}, \mathrm{p}=0.001\right)$, while an almost linear course was observed in anti-CCP-negative subjects $\left(\beta_{\text {time }}{ }^{2}=\right.$ $-1.3 \times 10^{-6}, \mathrm{p}=0.77$; Figure 2B).

From baseline and 12 months onward, COMP increased in anti-CCP-positive patients [9 U/l (IQR 7.8-11.8) vs $11.3 \mathrm{U} / 1$ (8.6-14); $\mathrm{p}<0.001]$, while there was no significant difference in anti-CCP-negative subjects during this period [10.5 U/1 (8.4-13.1) vs 11.3 U/1 (8.7-13.7); $\mathrm{p}=0.55]$. Although not statistically significant, COMP tended to decrease from years 1 through 4 in anti-CCP-positive patients [11.3 U/1 (8.6-14) vs

Personal non-commercial use only. The Journal of Rheumatology Copyright (c) 2011. All rights reserved. 
Table 1. Associations between cartilage oligomeric matrix protein (COMP) and clinical variables at baseline in patients with early untreated rheumatoid arthritis. Spearman rank correlation rho values.

\begin{tabular}{|c|c|c|c|}
\hline Characteristic & $\begin{array}{c}\text { COMP at Baseline, } \\
\qquad \mathrm{n}=160\end{array}$ & $\begin{array}{l}\text { COMP at Baseline, } \\
\text { Anti-CCP-positive, } \\
\qquad n=93\end{array}$ & $\begin{array}{c}\text { COMP at Baseline, } \\
\text { Anti-CCP-negative, } \\
\qquad n=66\end{array}$ \\
\hline C-reactive protein & 0.10 & 0.13 & 0.14 \\
\hline DAS28 & $0.28 * *$ & $0.28 * *$ & $0.27 *$ \\
\hline No. swollen joints & $0.39 * *$ & $0.32 * *$ & $0.47 * *$ \\
\hline No. tender joints & $0.29 * *$ & $0.27 * *$ & $0.26^{*}$ \\
\hline MRI synovitis score ${ }^{\dagger}$ & $0.25 * *$ & $0.22 *$ & $0.32 *$ \\
\hline MRI erosion score ${ }^{\dagger}$ & $0.25 * *$ & $0.37 * *$ & 0.13 \\
\hline MRI edema score ${ }^{\dagger}$ & $0.18 *$ & $0.26^{*}$ & 0.14 \\
\hline HAQ & 0.11 & 0.20 & 0.04 \\
\hline VAS global & 0.07 & 0.10 & 0.05 \\
\hline VAS pain & 0.09 & 0.17 & -0.02 \\
\hline VAS physician & $0.34 * *$ & $0.25 *$ & $0.44 * *$ \\
\hline
\end{tabular}

$* \mathrm{p} \leq 0.05 ; * * \mathrm{p} \leq 0.01 . \dagger$ Contrast-enhanced MRI of nondominant wrist $(\mathrm{n}=135)$. CCP: cyclic citrullinated peptides; DAS28: Disease Activity Score including 28 joints; VAS: visual analog scale score; HAQ: Health Assessment Questionnaire.

10.2 U/l (8.3-13.4); $\mathrm{p}=0.82)$. This trend was not observed among anti-CCP-negative individuals.

COMP and imaging data. The wrist-only MRI group ( $\mathrm{n}=$ $135)$ and the wrist+MCP MRI group $(\mathrm{n}=93)$ did not differ in baseline variables including anti-CCP status ${ }^{19}$. Baseline COMP correlated significantly, although weakly, with MRI wrist-only erosion and synovitis scores (rho $=0.25, \mathrm{p}=$ 0.0043 , and rho $=0.25, \mathrm{p}=0.0039$, respectively). Stratifying the cohort according to anti-CCP status, COMP correlated similarly to the erosion score in anti-CCP-positive individuals $(\mathrm{n}=$ 81) but not in anti-CCP-negative individuals $(\mathrm{n}=53$; Table 1$)$. By contrast, COMP was weakly associated with synovitis score in anti-CCP-negative individuals (Table 1). In the wrist+MCP MRI group the same trend was observed for the erosion score [anti-CCP-positive $(\mathrm{n}=53)$ : rho $=0.28, \mathrm{p}=0.04$; and anti-CCP-negative $(\mathrm{n}=36)$ : rho $=0.14, \mathrm{p}=0.40]$, but not for the synovitis score (data not shown). The MRI edema score was associated with COMP in the anti-CCP-positive patients in the wrist-only and wrist+MCP MRI groups (rho $=0.26, \mathrm{p}=$ 0.017 , and rho $=0.32, \mathrm{p}=0.016$, respectively).

\section{DISCUSSION}

In this study, we add to previous evidence that COMP in the circulation is increased in patients with newly diagnosed RA. Of note, however, this increment was less pronounced in anti-CCP-positive compared to anti-CCP-negative individuals, and in addition, there was an inverse correlation between COMP in serum and anti-CCP titer. Further, we found that in anti-CCP-positive individuals, circulating COMP followed a parabolic 4-year course, whereas there was an almost linear pattern in anti-CCP-negative patients. In anti-CCP-positive patients, COMP was associated with MRI erosion and edema score, while COMP correlated positively with MRI synovitis scores in anti-CCP-negative subjects.

Our finding of lower COMP in anti-CCP-positive com- pared with anti-CCP-negative patients is in accord with a recent report by Turesson, et al $l^{11}$. These authors reported that individuals who developed RA had higher prediagnostic COMP levels 1-2 years before RA diagnosis compared with matched controls, but that this increment was particularly prevalent in anti-CCP-negative preclinical $\mathrm{RA}^{11}$.

In a study on the N-propeptide of collagen IIA (PIIANP), a marker of collagen II anabolism, we found that circulating PIIANP was significantly lower in anti-CCP-positive compared to anti-CCP-negative patients with $\mathrm{RA}^{12}$. In addition, there was a negative correlation between PIIANP and anti-CCP titer. These observations support the thesis that antibodies against citrullinated peptides may have a cartilage-suppressive effect. This is supported by chondrocyte culture studies and animal experiments, where antibodies against citrullinated peptides, e.g., collagen II and fibrinogen, have been reported to induce arthritis and to aggravate preexisting experimental arthritis ${ }^{27,28,29}$. Considering that bone marrow edema has been shown to be a strong predictor of future erosive progression ${ }^{18,19}$, the potential pathogenicity of anti-CCP is further supported in this study, where we report a positive correlation between COMP and MRI edema and erosion scores in patients who are anti-CCP-positive. Further evidence for differential pathogenic pathways in anti-CCP-positive and antiCCP-negative RA patients appears from the correlation between COMP and MRI synovitis scores and not erosion scores in anti-CCP-negative subjects observed in our study.

The CIMESTRA treatment protocol on which this study is based has been reported to be particularly efficient with respect to suppression of signs and symptoms of RA and erosive progression ${ }^{13,18,26}$. Since COMP is considered to be an integral component in cartilage growth and regeneration ${ }^{30,31}$, it would be anticipated that suppression of joint inflammation would lead to increased formation and release of COMP into the circulation. This is supported by the COMP increment fol-

Personal non-commercial use only. The Journal of Rheumatology Copyright $@$ C 2011. All rights reserved. 

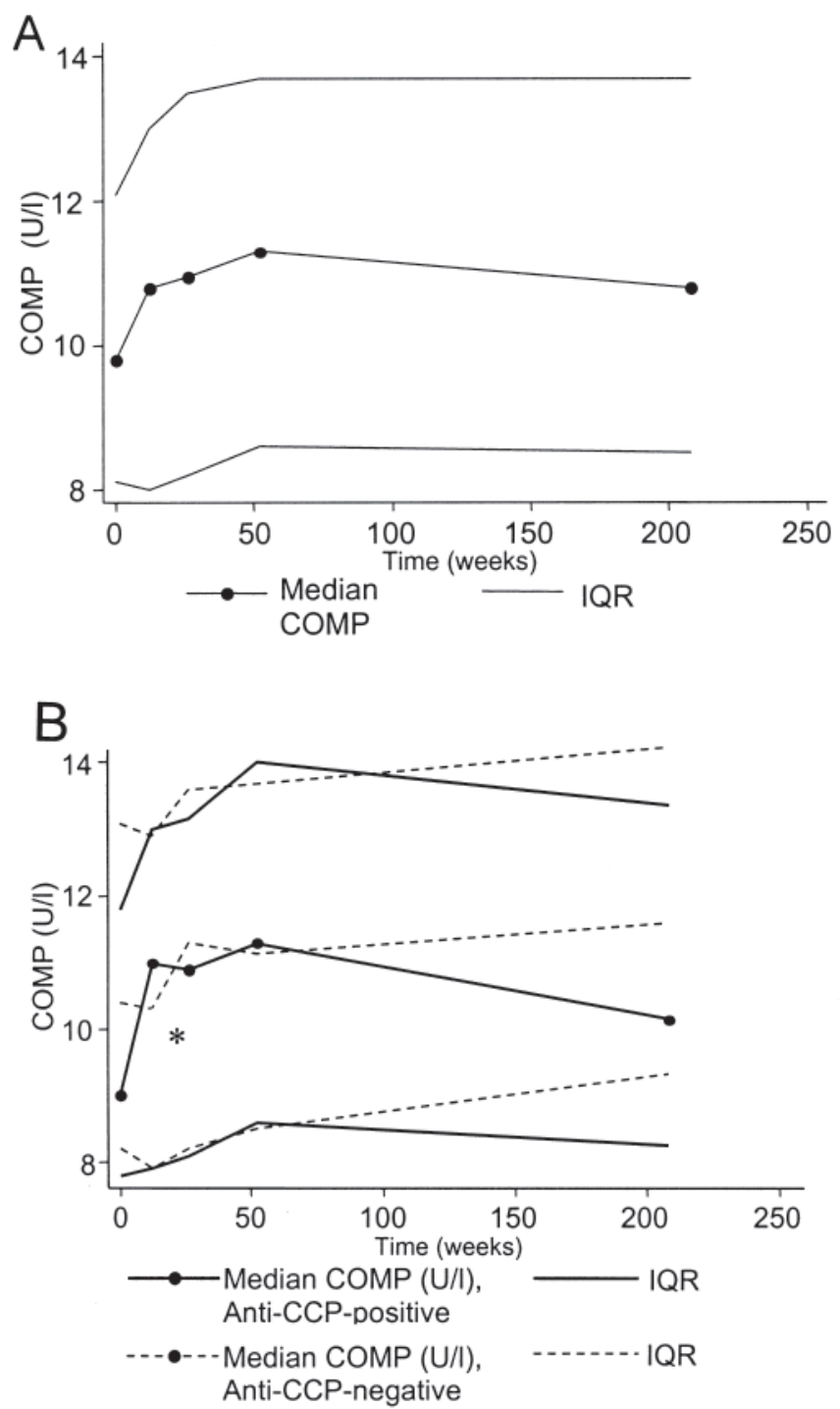

Figure 2. A. Serial COMP measurements in newly diagnosed RA from baseline through 4 years. Data are median, interquartile range (IQR). B. Serial COMP measurements in newly diagnosed RA from baseline through 4 years by anti-CCP status. Data are median, interquartile range (IQR). $* \mathrm{p}=0.048$.

lowing initiation of synovitis-suppressive treatment (Figure 2A). However, the parabolic course in the anti-CCP-positive subset, which exhibited a peak value followed by gradual decline through years $1-4$, probably reflects that complete regeneration of cartilage metabolism cannot be achieved despite early and aggressive treatment. Thus, the lower COMP in longstanding RA among anti-CCP-positive individuals may reflect a modifier effect by these autoantibodies on cartilage metabolism. Alternatively, these different patterns may reflect that increased cartilage turnover occurs in a subset that is distinct from the RA phenotype characterized by anti-CCP, and that COMP may have different implications in these 2 disease categories. In addition, in anti-CCP-positive patients, paracrine and/or autocrine signaling from the juxtaarticular bone compartment may contribute to cartilage depletion, as shown by the baseline association between COMP and MRI edema score in anti-CCP-seropositive patients. The potential significance of anti-CCP antibodies is emphasized by the observation that COMP did not differ according to shared epitope status or smoking habit. This indicates that anti-CCP antibodies interfere with RA disease mechanisms that are not shared with these well established risk factors for RA.

The study has some limitations and issues to be considered. First, COMP was measured only once in the control cohort, implying that potential temporal changes related to, for example, age or future health status are missed. Second, approximately $40 \%$ failed to complete the study followup. However, there was no difference with respect to baseline characteristics between completers and noncompleters and the intention-to-treat analysis included a large majority of the cohort. Third, the CIMESTRA cohort was offered intraarticular betamethasone injections whenever swollen joints were present. Hence, the different temporal courses of COMP according to anti-CCP status could in theory be attributable to different steroid dosing in the 2 subsets. However, no difference was observed between the 2 subsets with respect to their cumulative steroid doses.

Our study provides further evidence for the existence of different disease pathways between anti-CCP-positive and anti-CCP-negative subsets of RA, and evidence that anti-CCP antibodies may be implicated in the disease process by modifying cartilage metabolism.

\section{ACKNOWLEDGMENT}

We appreciate the expert laboratory assistance by Kirsten Junker at Medical Biotechnology Centre, University of Southern Denmark, Odense; Prof. Peter Garred at the Department of Clinical Immunology at Rigshospitalet, Copenhagen University Hospital; and Prof. Niels Heegaard at the Department of Biochemistry and Immunology, Statens Serum Institut, Denmark.

\section{REFERENCES}

1. Di Cesare PE, Carlson CS, Stollerman ES, Chen FS, Leslie M, Perris R. Expression of cartilage oligomeric matrix protein by human synovium. FEBS Letters 1997;412:249-52.

2. Hecht JT, Deere M, Putnam E, Cole W, Vertel B, Chen H, et al. Characterization of cartilage oligomeric matrix protein (COMP) in human normal and pseudochondroplasia musculoskeletal tissues. Matrix Biol 1998;17:269-78.

3. Oldberg A, Antonsson P, Lindblom K, Heinegard D. COMP (cartilage oligomeric matrix protein) is structurally related to the thrombospondins. J Biol Chem 1992;267:22346-50.

4. Neidhardt M, Hauser N, Paulsson M, Di Cesare PE, Michel BA, Häuselmann HJ. Small fragments of cartilage oligomeric matrix protein in synovial fluid and serum as markers for cartilage degradation. Br J Rheumatol 1997;36:1151-60.

5. Forslind K, Eberhardt K, Jonsson A, Saxne T. Increased serum concentrations of cartilage oligomeric matrix protein. A prognostic marker in early rheumatoid arthritis. Rheumatology 1992;31:593-8.

6. Lindqvist E, Eberhardt K, Bendtzen K, Heinegard D, Saxne T. Prognostic laboratory makers of joint damage in rheumatoid arthritis. Ann Rheum Dis 2005;64:196-201.

7. Skoumal M, Kolarz G, Klingler A. Serum levels of cartilage oligomeric matrix protein. Scand J Rheumatol 2003;32:156-61 
8. Fex E, Eberhardt K, Saxne T. Tissue-derived macromolecules and markers of inflammation in serum in early rheumatoid arthritis: relationship to development of joint destruction in hands and feet. Br J Rheumatol 1997;36:1161-5.

9. Roux-Lombard P, Eberhardt K, Saxne T, Dayer JM, Wollheim FA. Cytokines, metalloproteinases, their inhibitors and cartilage oligomeric matrix protein: relationship to radiological progression and inflammation in early rheumatoid arthritis. A prospective 5-year study. Rheumatology 2001;40:544-51.

10. de Jong Z, Munneke M, Vilim V, Zwinderman AH, Kroon HM, Ronday HK, et al. Value of serum cartilage oligomeric matrix protein as a prognostic marker of large-joint damage in rheumatoid arthritis - data from the RAPIT study. Rheumatology 2008;47:868-71.

11. Turesson C, Bergstrøm U, Jacobsson LTH, Truedsson L, Berglund $\mathrm{G}$, Saxne T. Increased cartilage turnover and circulating autoantibodies in different subsets before the clinical onset of rheumatoid arthritis. Ann Rheum Dis 2011;70:520-2.

12. Christensen AF, Hørslev-Petersen K, Christgau S, Lindegaard HM, Lottenburger T, Junker K, et al. Uncoupling of collagen II metabolism in newly diagnosed, untreated rheumatoid arthritis is linked to inflammation and antibodies against cyclic citrullinated peptides. J Rheumatol 2010;37:1113-20.

13. Hetland ML, Stengaard-Pedersen K, Junker P, Lottenburger T, Ellingsen T, Andersen LS, et al. Combination treatment with methotrexate, cyclosporine, and intraarticular betamethasone compared with methotrexate and intraarticular betamethasone in early active rheumatoid arthritis: an investigator initiated, multicenter, randomized, double blind, parallel group, placebo controlled study. Arthritis Rheum 2006;54:1401-9.

14. Arnett FC, Edworthy SM, Bloch DA, McShane DJ, Fries JF, Cooper NS, et al. The American Rheumatism Association 1987 revised criteria for the classification of rheumatoid arthritis. Arthritis Rheum 1988;31:315-24.

15. Thorsen H, Hansen TM, McKenna SP, Sørensen SF, Whalley D. Adaption into Danish of the Stanford Health Assessment Questionnaire (HAQ) and the Rheumatoid Arthritis Quality of Life Scale (RaQol). Scand J Rheumatol 2001;30:103-9.

16. Prevoo MLL, van 't Hof MA, Kuper HH, van Leeuwen MA, van de Putte LBA, van Riel PL. Modified disease activity scores that include twenty-eight-joint counts. Arthritis Rheum 1995;38:44-8.

17. Felson DT, Anderson JJ, Boers M, Bombardier C, Furst D, Goldsmith C, et al. American College of Rheumatology. Preliminary definition of improvement in rheumatoid arthritis. Arthritis Rheum 1995;38:727-35.

18. Hetland M, Stengaard-Pedersen K, Junker P, Østergaard M, Ejbjerg $\mathrm{BJ}$, Jacobsen S. Radiographic progression and remission rates in early rheumatoid arthritis - MRI bone oedema and anti-CCP predicted radiographic progression in the 5-year extension of the double-blind randomised CIMESTRA trial. Ann Rheum Dis 2010;69:1789-95.

19. Hetland M, Ejbjerg B, Horslev-Petersen K, Jacobsen S, Vestergaard A, Jurik AG, et al. MRI bone oedema is the strongest predictor of subsequent radiographic progression in early rheumatoid arthritis. Results from a 2 year randomized controlled trial (CIMESTRA). Ann Rheum Dis 2009;68:384-90.
20. Østergaard M, Peterfy C, Conaghan P, McQueen F, Bird P, Ejbjerg B, et al. OMERACT Rheumatoid Arthritis Magnetic Resonance Imaging Studies. Core set of MRI acquisitions, joint pathology definitions, and the OMERACT RA-MRI scoring system. J Rheumatol 2003;30:1385-6.

21. Saxne T, Heinegård D. Cartilage oligomeric matrix protein: a novel marker of cartilage turnover detectable in synovial fluid and blood. Br J Rheumatol 1992;31:583-91.

22. Nishimura K, Sugiyama D, Kogata Y, Tsuji G, Nakazawa T, Kawano S, et al. Meta-analysis: Diagnostic accuracy of anti-cyclic citrullinated peptide antibody and rheumatoid factor for rheumatoid arthritis. Ann Intern Med 2007;146:797-808.

23. Høier-Madsen M, Nielsen LP, Møller S. Determination of IgM rheumatoid factors by enzyme-linked immunosorbent assay (ELISA). Ugeskr Laeger 1986;148:2018-21.

24. Vasiliauskiene L, Wiik A, Hoier-Madsen M. Prevalence and clinical significance of antikeratin antibodies and other serological markers in Lithuanian patients with rheumatoid arthritis. Ann Rheum Dis 2001;60:459-66

25. Kimura A, Sasazuki T. Eleventh International Histocompatibility workshop reference protocol for the HLA DNA typing technique. In: Tsuji K, Aizawa M, Sasazuki M, editors. Oxford: Oxford University Press; 1992.

26. Hetland ML, Stengaard-Pedersen K, Junker P, Lottenburger T, Hansen I, Andersen LS, et al. Aggressive combination therapy with intraarticular glucocorticoid injections and conventional DMARDs in early rheumatoid arthritis: second-year clinical and radiographic results from the CIMESTRA study. Ann Rheum Dis 2008;67:815-22.

27. Kuhn KA, Kulik L, Tomooka B, Braschler KJ, Arend WP, Robinson WH, et al. Antibodies against citrullinated proteins enhance tissue injury in experimental autoimmune arthritis. J Clin Invest 2006;116:961-73.

28. Lundberg K, Nijenhuis S, Vossenaar ER, Palmblad K, van Venrooij WJ, Klareskog L, et al. Citrullinated proteins have increased immunogenicity and arthritogenicity and their presence in arthritic joints correlates with disease severity. Arthritis Res Ther 2005;7:R458-67.

29. van Lent PL, Grevers L, Lubberts E, de Vries TJ, Nabbe KC, Verbeek S, et al. Fcgamma receptors directly mediate cartilage, but not bone, destruction in murine antigen-induced arthritis: Uncoupling of cartilage damage from bone erosions and joint inflammation. Arthritis Rheum 2006;54:3868-77.

30. Halasz K, Kassner A, Morgelin M, Heinegard D. COMP acts as a catalyst in collagen fibrillogenesis. J Biol Chem 2007;282:31166-73.

31. Mann HH, Ozbek S, Engel J, Paulsson M, Wagener R. Interactions between the cartilage oligomeric matrix protein and matrilins: implications for matrix assembly and the pathogenesis of chondrodysplasias. J Biol Chem 2004;279:25294-8. 